\title{
Quest for the optimal technique of laparoscopic splenectomy - vessels first or hilar transection?
}

\author{
Dorota Radkowiak ${ }^{1}$, Anna Zychowicz ${ }^{1}$, Michał Wysocki ${ }^{1,2}$, Anna Lasek ${ }^{1}$, Piotr Major ${ }^{1,2}$, Michał Pędziwiatr ${ }^{1,2}$, \\ Piotr Budzyński ${ }^{1}$, Marcin Dembiński ${ }^{1}$, Jadwiga Dworak ${ }^{1}$, Andrzej Budzynski ${ }^{1,2}$ \\ ${ }^{1} 2^{\text {nd }}$ Department of General Surgery, Jagiellonian University Medical College, Krakow, Poland \\ ${ }^{2}$ Centre for Research, Training and Innovation in Surgery (CERTAIN Surgery), Krakow, Poland
}

Videosurgery Miniinv 2018; 13 (4): 460-468 DOI: https://doi.org/10.5114/wiitm.2018.76071

\begin{abstract}
Introduction: Throughout our 20 years of experience, we have used several different techniques for laparoscopic splenectomy (LS). However, two methods have been used most frequently: "vessels first" and "hilar transection". Aim: To evaluate the outcomes of LS performed with these two different approaches.

Material and methods: It was an observational study based on retrospective analysis of consecutive patients undergoing LS in a tertiary referral surgical center in the period 1998-2017. We excluded patients with splenic trauma, initially submitted to open surgery, stapled transection of splenic hilum, partial resections of the spleen and other spleen-preserving procedures. Patients were divided into two groups: group 1 ("vessels first") with 188 patients, and group 2 ("hilar transection") with 287 patients.

Results: Mean operative time was shorter ( $p<0.001)$ and blood loss was lower $(p<0.001)$ in group 2. The need for blood transfusions and the conversion rate were higher in group 1 ( $p=0.044$ and $p=0.003$ respectively). There was no difference in intraoperative adverse events $(p=0.179)$. Overall postoperative morbidity did not differ between groups ( $p=0.081$ ) and we noted mortality of $0.21 \%$ (1 patient of group 2$)$. The morbidity rate associated with accidental injury of the pancreatic parenchyma was significantly higher in group 1 ( $p=0.028)$. Median length of hospital stay was 4 days (range: $1-99)$ and did not differ between groups ( $p=0.175)$.

Conclusions: The "vessels first" technique is associated with longer operative time, higher blood loss and increased risk of conversion. "Hilar transection" is associated with lower incidence of local complications related most likely to accidental injury of the pancreatic tail. In the case of a large caliber of splenic vessels the "vessels first" approach remains the technique of choice.
\end{abstract}

Key words: laparoscopy, spleen, splenectomy, vessels first, hilar transection, morbidity, mortality.

\section{Introduction}

There is some controversy as to who (and when) exactly performed the first laparoscopic splenectomy (LS) [1]. The year 1991 and the author Carroll et al. [2] or (more likely) Delaitre and Maignien [3, 4] are most frequently mentioned. Anyway, this procedure has been available for more than a quarter of a centu- ry and has replaced in most centers traditional, open splenectomy (OP). Even though many authors share the opinion about the "standardized approach" there are some important differences regarding the surgical technique. Some reports concentrate mostly on the access to the peritoneal cavity, discussing differences between 4-port laparoscopy, SILS, Hand-assisted laparoscopic surgery (HALS) etc. However, regarding

\section{Address for correspondence}

Michał Wysocki, $2^{\text {nd }}$ Department of General Surgery, Jagiellonian University Medical College, 21 Kopernika St, 31-501 Krakow, Poland, phone: +48 697307685 , e-mail: michal92wysocki@gmail.com 
postoperative course this seems to be of lesser importance than the technique of dissection and control of splenic vascular supply. Throughout the 20 years of our experience, with more than 500 laparoscopic operations of the spleen, we have attempted to use several different techniques. However, two methods, differing in approach to the splenic vessels, referred to as "vessels first" and "hilar transection", have been used most frequently.

\section{Aim}

The aim of the study was to evaluate the outcomes of LS performed with two different approaches: "vessels first" and "hilar transection".

\section{Material and methods}

\section{Design}

This observational study design was based on retrospective analysis of prospectively collected data in all consecutive patients undergoing laparoscopic operations of the spleen (total splenectomy as well as spleen-sparing procedures) in a tertiary referral university surgical center in 1998-2017. Inclusion criteria were: elective total splenectomy performed for hematological disorders, pure laparoscopic or single incision approach, "vessels first" or "hilar transection" technique for control of the vascular supply. We excluded patients with splenic trauma, initially submitted to open surgery, stapled transection of the splenic hilum, partial resections of the spleen and other spleen-preserving procedures. Patients were divided by operative technique used during the operation and analyzed in two groups: group 1 ("vessels first"), and group 2 ("hilar transection").

\section{Outcomes}

The primary outcomes were related to the assessment of the course of the procedure and included operative time, conversion rate, intraoperative blood loss and intraoperative adverse events/complications. Operative time was measured from skin incision to closure. The intraoperative blood loss was measured from the amount of blood aspirated in the suction machine. Intraoperative adverse events/ complications were defined as any iatrogenic harmful event occurring during the operation, which had not derived from the standard technique. Intraoperative blood loss equal to or greater than $500 \mathrm{ml}$ was considered to be a hemorrhage and was included as an intraoperative complication, because losing less than one unit of blood $(\approx 500 \mathrm{ml})$ usually does not negatively affect the condition of the patient and does not lead to hypovolemia and hemorrhagic shock $[5,6]$. Indications for transfusion were: hemorrhagic shock, hemoglobin $\leq 6 \mathrm{~g} \%$ or $6-8 \mathrm{~g} \%$ in case of evidence for limited compensation and risk factors (e.g. coronary heart disease, systolic heart failure, insufficient cerebral vascular flow) or presence of the following symptoms: tachycardia, hypotension, acute coronary ischemia in ECG, acidosis [7].

The secondary outcomes included parameters of the postoperative course: 30-day postoperative morbidity (graded with Clavien-Dindo classification [8]), mortality, reoperations and length of stay. $W$ paid special attention to complications that might have resulted directly from the operative technique, i.e. related to potential injury of the pancreatic tail. We defined reoperations as a subsequent operation performed due to a postoperative complication after LS. The length of stay (LOS) was measured from the admission day until discharge.

\section{Operative technique}

In our department the primary choice of the operative access to the peritoneal cavity during LS is a laparoscopic 4-port technique. During the study period seven patients were operated on through a single incision, but after a feasibility study this technique was abandoned [9, 10]. Hand-assisted laparoscopic surgery was used only in 5 cases as an alternative to full conversion, but never electively. Regardless of the access to the peritoneal cavity the course of LS was standardized. Patients were operated on in the right lateral decubitus position. At the beginning of all operations transection of the gastro-splenic ligament and short gastric vessels with various energy devices was performed. This was followed by extensive lateral mobilization of the spleen. There were however two different techniques of control of splenic vessels. At the beginning of our experience we used in all cases the technique referred to as "vessels first", described elsewhere [11, 12]. In this technique the main trunks of the splenic artery and vein were identified at the level of the pancreatic body/tail, isolated, clipped and transected. Than the entire splenic hilum including branches of all vessels, perivascular fat and lymphatic tissue 
was dissected away in one block from the pancreatic tail and removed together with the spleen (Photo 1). This approach does not require the use of a stapler, and because of its cost-effectiveness it was initially adopted for standard use during all LS. However, this technique has been mostly abandoned nowadays and is used only for patients with a particularly large caliber of splenic vessels, i.e. portal hypertension or splenomegaly.

Nowadays a different technique, referred to as "hilar transection", has been introduced. In this approach the main, nominate splenic vessels are not isolated. The entire splenic hilum is transected, as close as possible to the splenic parenchyma, with a new generation of energy devices - Ligasure (Covidien) and more recently Thunderbeat (Olympus) (Photo 2). Both allow for safe closure of the vascular branches in the splenic hilum without use of staples. Occasionally some clips are applied on larger branches of vessels in the hilum, and the decision about their use belongs to the operating surgeon.

\section{Ethics}

The study was conducted according to the Report of the ISPOR Task Force on Retrospective Databases [13]. To ensure the quality of published studies that use health-related retrospective databases, a checklist that focuses on issues that are unique to database studies or are particularly problematic in database research was developed. Checklist ques-

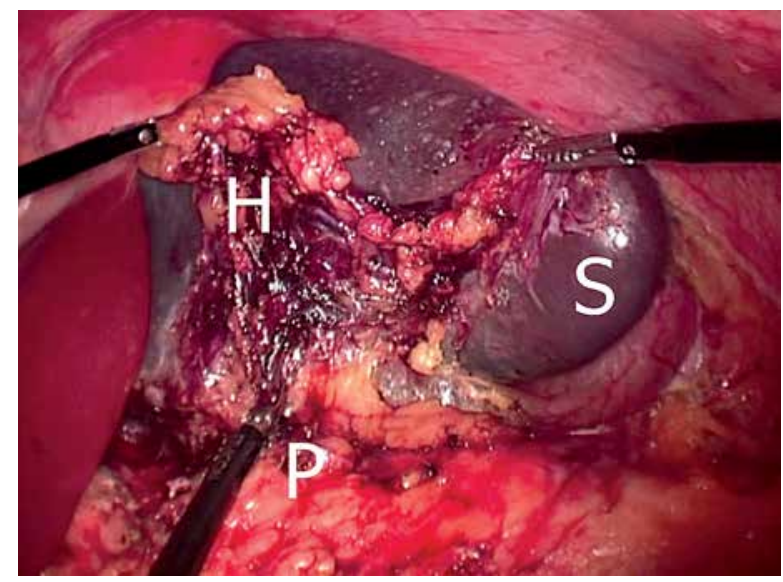

Photo 1. Laparoscopic splenectomy performed according to the "vessels first" approach. The entire splenic hilum is dissected together with the spleen from the pancreatic tail

$S$-spleen, $H$-splenic hilum, $P$ - pancreas. tions cover a wide range of issues, including relevance, reliability and validity, data linkages, eligibility determination, research design, treatment effects, sample selection, censoring, variable definitions, resource valuation, statistical analysis, generalizability, and data interpretation. All procedures followed the ethical standards of the responsible committee on human experimentation (institutional and national) and the 2013, Fortaleza revision of the 1975 Declaration of Helsinki. The study was approved by an independent ethics committee of the Jagiellonian University, Krakow, Poland (approval number 1072/6120/160/2017). Informed consent for the surgical treatment was obtained from all patients before the procedure.

\section{Statistical analysis}

All data were analyzed with StatSoft Statistica v.12.5 (StatSoft Inc, Tulsa, Oklahoma, USA). The results are presented as mean \pm standard deviation $(\mathrm{SD})$, median and interquartile range (IQR), when appropriate. The study of categorical variables used Pearson's $\chi^{2}$ test, or $\chi^{2}$ with Yates' correction, when appropriate. The Shapiro-Wilk test was used to check for normal distribution of data. Quantitative data were analyzed with Student's $t$-test (for normally distributed data) and the Mann-Whitney test (for non-normally distributed data). Results were considered statistically significant when the $p$-value was found to be less than 0.05 .

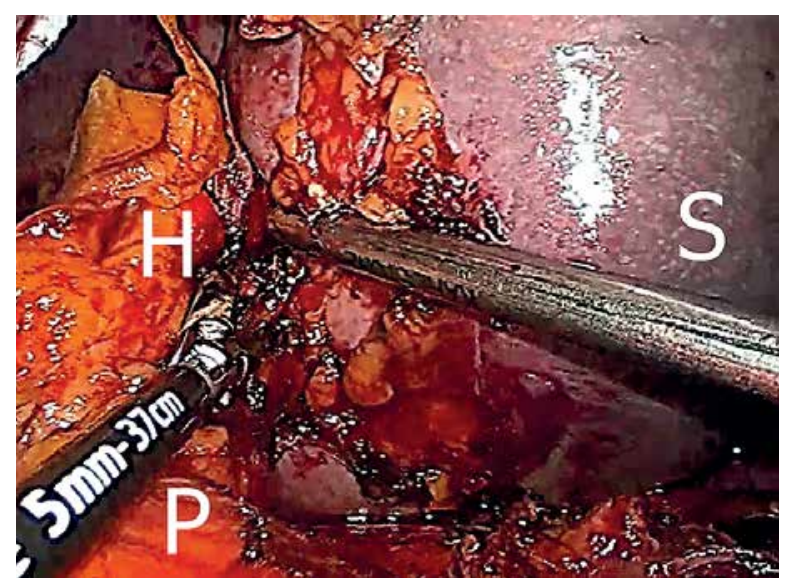

Photo 2. Laparoscopic splenectomy performed according to the "hilar transection" approach. The splenic hilum is transected at the level of the splenic parenchyma with an energy device

$\mathrm{S}$-spleen, $\mathrm{H}$-splenic hilum, $\mathrm{P}$ - pancreas. 


\section{Material}

In the period 1998-2017, we performed 545 laparoscopic operations of the spleen. The most common procedure was LS, which was performed in 487 patients. Seventy-two patients were excluded from the study group. The flow chart (Figure 1) presents the design of the study group in detail and reasons for exclusion. There were 188 patients included in group 1 ("vessels first"), and 287 in Group 2 ("hilar transection").

The study group consisted of $303(63.79 \%)$ women and 172 (36.21\%) men. The median age was 45 (15-84) years. The indications for splenectomy are presented in Table I. The analyzed groups did not differ in demographics parameters. The details of data in both subgroups are presented in Table II.

\section{Results}

The median operative time in the entire group was 100 (75-130) min. The median blood loss in the whole study was $50 \mathrm{ml}$ (min.-max.: 0-1500; IQR: 20-150). A total of 34 patients required blood transfusion of 1-9 units of packed red blood cells. The

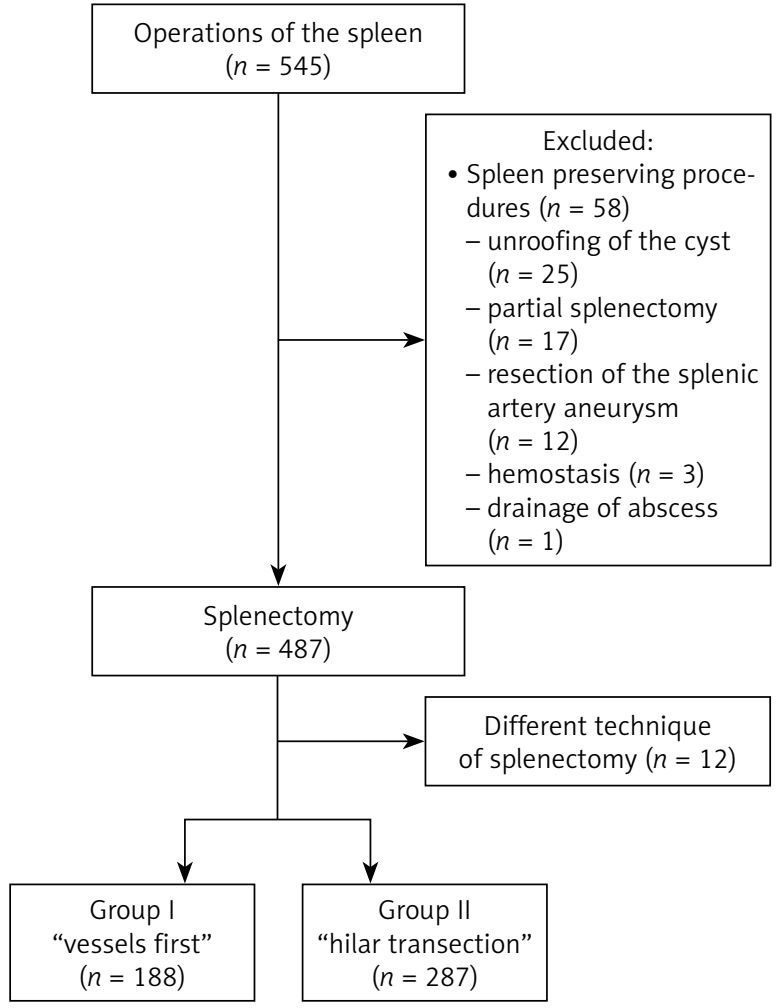

Figure 1. Flowchart of patients through the study

Table I. Indications for LS

\begin{tabular}{|c|c|c|c|c|c|c|}
\hline \multirow[t]{2}{*}{ Indication } & \multicolumn{2}{|r|}{ Total } & \multicolumn{2}{|r|}{ Group 1} & \multicolumn{2}{|r|}{ Group 2} \\
\hline & $N(\%)$ & $\begin{array}{l}\text { Size of the spleen, } \\
\text { median }(\mathrm{IQR})[\mathrm{cm}]\end{array}$ & $N(\%)$ & $\begin{array}{l}\text { Size of the spleen, } \\
\text { median }(\mathrm{IQR})[\mathrm{cm}]\end{array}$ & $N(\%)$ & $\begin{array}{l}\text { Size of the spleen, } \\
\text { median }(\mathrm{IQR})[\mathrm{cm}]\end{array}$ \\
\hline ITP & $254(53.47)$ & $11.5(10-13)$ & $99(52.66)$ & $11(10-13)$ & $155(54.01)$ & $12(10-13)$ \\
\hline Lymphoma & $101(21.26)$ & $19(17-23)$ & $43(22.88)$ & $20(18-27)$ & $58(20.21)$ & $17(15.5-20)$ \\
\hline Spherocytosis & $32(6.74)$ & $17.5(15-20)$ & $15(7.97)$ & $18(15-22)$ & $17(5.93)$ & $17(16-20)$ \\
\hline Autoimmune anemia & $23(4.84)$ & $15(14-17)$ & $9(4.79)$ & $17(15-17)$ & $14(4.88)$ & $14(12.5-17)$ \\
\hline Tumor & $20(4.21)$ & $14(11-15.5)$ & $1(0.54)$ & $17(17-17)$ & $19(6.63)$ & $14(10-15)$ \\
\hline Splenomegaly & $22(4.63)$ & $18(16-20)$ & $12(6.38)$ & $20(18-30)$ & $10(3.48)$ & $16.5(15-18)$ \\
\hline Leukemia & $9(1.89)$ & $18(17-22)$ & $5(2.66)$ & $20(17-25)$ & $4(1.39)$ & $17.5(14.75-20)$ \\
\hline Other: & $14(2.95)$ & $15(12-20)$ & $4(2.13)$ & $25(20-35)$ & $10(3.48)$ & $14.5(11-15.5)$ \\
\hline Sarcoidosis & 4 & & 0 & & 4 & \\
\hline $\begin{array}{l}\text { Splenic artery } \\
\text { aneurysm }\end{array}$ & 3 & & 1 & & 2 & \\
\hline Osteomyelofibrosis & 2 & & 2 & & 0 & \\
\hline Splenic cyst & 4 & & 0 & & 4 & \\
\hline Gaucher disease & 1 & & 1 & & 0 & \\
\hline Total & 475 (100) & $14(11-17)$ & 188 & 15 (11-20) & 287 & $13(11-17)$ \\
\hline
\end{tabular}


overall conversion rate was $3.16 \%$, and the intraoperative complication rate was $5.68 \%$. Analysis of the parameters related to the course of the procedure included in the primary outcomes are presented in Table III.

Table II. Patients' characteristics

\begin{tabular}{|c|c|c|c|}
\hline Parameter & Group 1 & Group 2 & $P$-value \\
\hline Number of patients & 188 & 287 & - \\
\hline \multicolumn{3}{|l|}{ Age [years]: } & \multirow[t]{2}{*}{$0.001^{1}$} \\
\hline Median & 40 & 50 & \\
\hline IQR & $23-55.5$ & \multicolumn{2}{|l|}{$31-60$} \\
\hline Range & $15-84$ & \multicolumn{2}{|l|}{$17-84$} \\
\hline Female, $n(\%)$ & $124(65.96)$ & $179(62.37)$ & \multirow[t]{2}{*}{$0.426^{2}$} \\
\hline Male, $n(\%)$ & $64(34.04)$ & $108(37.63)$ & \\
\hline ASA $1, n(\%)$ & $43(22.87)$ & $68(23.69)$ & \multirow[t]{4}{*}{$0.804^{2}$} \\
\hline ASA 2, n (\%) & $58(30.85)$ & $81(28.22)$ & \\
\hline ASA 3, $n(\%)$ & $49(26.06)$ & $85(29.62)$ & \\
\hline ASA 4, n (\%) & $38(20.21)$ & $53(18.47)$ & \\
\hline \multicolumn{3}{|c|}{ Size of the spleen $[\mathrm{cm}]$ : } & $<0.001^{1}$ \\
\hline Median & 15 & 13 & \\
\hline IQR & $11-20$ & $11-17$ & \\
\hline Range & $9-37$ & $4-30$ & \\
\hline
\end{tabular}

Table III. Analysis of intraoperative parameters in subgroups

\begin{tabular}{|c|c|c|c|}
\hline Parameter & Group 1 & Group 2 & $P$-value \\
\hline \multicolumn{3}{|l|}{ Operative time [min]: } & $<0.001^{1}$ \\
\hline Median & 135 & 90 & \\
\hline $\mathrm{IQR}$ & $100-160$ & $70-120$ & \\
\hline Range & $50-240$ & $25-280$ & \\
\hline \multicolumn{3}{|c|}{ Intraoperative blood loss [ml]: } & $<0.001^{1}$ \\
\hline Median & 100 & 50 & \\
\hline $\mathrm{IQR}$ & $50-400$ & 20-100 & \\
\hline Range & $10-1200$ & $0-1500$ & \\
\hline $\begin{array}{l}\text { Need for blood } \\
\text { transfusion, } n(\%)\end{array}$ & 19 (10.11) & $15(5.23)$ & $0.044^{2}$ \\
\hline Conversion, $n(\%)$ & $12(6.38)$ & $3(1.05)$ & $0.003^{3}$ \\
\hline $\begin{array}{l}\text { Intraoperative com- } \\
\text { plications, } n(\%)\end{array}$ & $14(7.45)$ & $13(4.53)$ & $0.179^{2}$ \\
\hline
\end{tabular}

${ }^{1}$ Mann-Whitney test, ${ }^{2}$ Pearson's $\chi^{2}$ test, ${ }^{3} \chi^{2}$ test with Yates' correction.
The average operative time in "hilar transection" group was shorter (135 min vs. 90 min respectively), and the difference was statistically significant $(p<0.001)$. The median blood loss was also significantly lower in the same group $(p<0.001)$. The conversion rate was higher in group $1(6.38 \%$ vs. $1.05 \%)$. The difference was statistically significant $(p=0.003)$. There was no difference in the rate of intraoperative adverse events between study groups $(p=0.179)$. Most intraoperative adverse events were accidental injuries of various organs, which were repaired laparoscopically. The second most common group was massive bleeding, which required conversion in half of the cases. The number and types of intraoperative complications along with reasons for conversions in both study groups are listed in Table IV.

Secondary outcomes reflecting safety of the procedure are listed in Table V. Overall postoperative morbidity was $8.42 \%$ (40 patients) and we noted mortality of $0.21 \%$ (1 patient). This patient was operated on

Table IV. Intraoperative adverse events and reasons for conversions

\begin{tabular}{|c|c|c|}
\hline Intraoperative adverse events & Group 1 & Group 2 \\
\hline \multicolumn{3}{|c|}{ Accidental injury of intra-abdominal organ: } \\
\hline Stomach & $3(1.59 \%)$ & $1(0.35 \%)$ \\
\hline Splenic flexure & 0 & $2(0.69 \%)$ \\
\hline $\begin{array}{l}\text { Diaphragm (sutured without } \\
\text { chest tube) }\end{array}$ & $2(1.06 \%)$ & 0 \\
\hline Small bowel & 0 & $1(0.35 \%)$ \\
\hline Pancreatic tail & 0 & $1(0.35 \%)$ \\
\hline Bladder (Pfannenstiel incision) & $1(0.53 \%)$ & 0 \\
\hline \multicolumn{3}{|l|}{ Massive bleeding: } \\
\hline Managed laparoscopically & $2(1.06 \%)$ & $4(1.39 \%)$ \\
\hline Requiring conversion & $2(1.06 \%)$ & $3(1.05 \%)$ \\
\hline Rupture of the retrieval bag & $4(2.13 \%)$ & $1(0.35 \%)$ \\
\hline Total & $14(6.38 \%)$ & $13(4.53 \%)$ \\
\hline Reasons for conversions & Group 1 & Group 2 \\
\hline Bleeding & $2(1.06 \%)$ & $3(1.05 \%)$ \\
\hline Technical problems & $4(2.13 \%)$ & 0 \\
\hline $\begin{array}{l}\text { Infiltration of surrounding } \\
\text { structures }\end{array}$ & $4(2.13 \%)$ & 0 \\
\hline Spleen's friability & $1(0.53 \%)$ & 0 \\
\hline Size of the spleen & $1(0.53 \%)$ & 0 \\
\hline Total & $12(7.45 \%)$ & $3(1.05 \%)$ \\
\hline
\end{tabular}


for massive splenomegaly caused by lymphoma. He was reoperated on classically $1 \mathrm{~h}$ after LS because of massive bleeding and again $2 \mathrm{~h}$ later for rebleeding with the need for CPR during surgery and eventually died in the intensive care unit (ICU).

There were more postoperative complications in the "vessels first" group (11.17\% vs. 6.62\%), but the difference was not significant $(p=0.081)$. However, the morbidity rate of complications attributed to accidental injury of the pancreatic parenchyma was significantly higher in group 1 (abscess or fluid collection in the splenic bed, pancreatitis, pancreatic fistula) (5.32\% vs. $1.39 \% ; p=0.028)$. Classification of perioperative ( $\leq 30$ days) complications according to the Clavien-Dindo classification is presented in Table VI. Median length of hospital stay was 4 days (range: 1-99) and did not differ between study groups $(p=0.175)$.
Table V. Analysis of secondary outcomes in subgroups

\begin{tabular}{|c|c|c|c|}
\hline Outcome & Group 1 & Group 2 & $P$-value \\
\hline $\begin{array}{l}\text { Postoperative } \\
\text { morbidity }\end{array}$ & 21 (11.17\%) & $19(6.62 \%)$ & $0.081^{1}$ \\
\hline $\begin{array}{l}\text { Complications } \\
\text { related to injury } \\
\text { of the pancreas }\end{array}$ & $10(5.32 \%)$ & $4(1.39 \%)$ & $0.028^{2}$ \\
\hline Reoperation & $8(4.25 \%)$ & 11 (3.83\%) & $0.635^{2}$ \\
\hline Mortality & 0 & 1 & - \\
\hline Length of stay [days]: & & & $0.175^{3}$ \\
\hline Median & 4 & 5 & \\
\hline$I Q R$ & $3-6$ & $4-6$ & \\
\hline Range & $3-99$ & $2-36$ & \\
\hline
\end{tabular}

${ }^{1}$ Pearson's $\chi^{2}$ test, ${ }^{2} \chi^{2}$ test with Yates' correction, ${ }^{3}$ Mann-Whitney test.

Table VI. Perioperative ( $\leq 30$ days) complications according to Clavien-Dindo grading

\begin{tabular}{|c|c|c|c|}
\hline C-D & Complications & Group 1 & Group 2 \\
\hline 5 & Massive intraoperative blood loss. Reoperation for recurrent hemorrhage (patient death) & 0 & $1(0.35 \%)$ \\
\hline $4 b$ & $\begin{array}{l}\text { Pancreatic fistula with abscess and secondary perforation of splenic flexure. Multiple } \\
\text { reoperations. Cardiorespiratory failure (ICU stay) }\end{array}$ & $1(0.53 \%)$ & 0 \\
\hline \multirow[t]{7}{*}{$3 b$} & Postoperative bleeding (relaparoscopy) & $2(1.06 \%)$ & $4(1.39 \%)$ \\
\hline & Subphrenic abscess (reoperation) & $3(1.59 \%)$ & $2(0.69 \%)$ \\
\hline & Acute pancreatitis (reoperation) & $1(0.53 \%)$ & $1(0.35 \%)$ \\
\hline & $\begin{array}{l}\text { Perforation of the fundus of the stomach probably due to thermal injury (reoperation on } \\
8^{\text {th }} \text { postoperative day) }\end{array}$ & 0 & $1(0.35 \%)$ \\
\hline & Subphrenic hematoma (operative drainage) & 0 & $1(0.35 \%)$ \\
\hline & Thrombosis of superior mesenteric artery (revascularization) & 0 & $1(0.35 \%)$ \\
\hline & Pancreatic fistula & $1(0.53 \%)$ & 0 \\
\hline \multirow[t]{4}{*}{$3 a$} & Subphrenic abscess (percutaneous drainage) & $1(0.53 \%)$ & $1(0.35 \%)$ \\
\hline & Port-site bleeding (suture ligation under local anesthesia) & 0 & $1(0.35 \%)$ \\
\hline & Pelvic hematoma (percutaneous drainage) & $1(0.53 \%)$ & 0 \\
\hline & Pneumothorax (chest tube) & 0 & $1(0.35 \%)$ \\
\hline \multirow[t]{5}{*}{2} & Fever of unknown origin & $4(2.13 \%)$ & $3(1.05 \%)$ \\
\hline & Pulmonary infection & $1(0.53 \%)$ & $1(0.35 \%)$ \\
\hline & Urinary tract infection & $1(0.53 \%)$ & 0 \\
\hline & Superior mesenteric vein thrombosis & $1(0.53 \%)$ & 0 \\
\hline & Subphrenic hematoma & 0 & $1(0.35 \%)$ \\
\hline \multirow[t]{3}{*}{1} & Subphrenic fluid collection & $3(1.59 \%)$ & 0 \\
\hline & Pneumothorax (spontaneous resolution) & $1(0.53 \%)$ & 0 \\
\hline & Total & $21(11.17 \%)$ & $19(6.62 \%)$ \\
\hline
\end{tabular}




\section{Discussion}

In this study based on the analysis of outcomes of 475 laparoscopic splenectomies we were able to document that there are important differences in the postoperative outcome related to the technique of dissection and control of splenic vessels. The approach referred to as "hilar transection" in which vessels are transected practically at the level of the splenic parenchyma was associated with lower overall morbidity and significantly lower rates of local complications related most likely to accidental injury of the pancreatic tail. This method is, however, of limited use in patients with a large caliber of splenic vessels in portal hypertension or massive splenomegaly due to different causes, where the "vessels first" approach remains the technique of choice.

Currently there is no doubt that laparoscopy is the preferred approach for splenectomy. The benefits of this operation have been documented in many studies. The results are surprisingly good, and LS has become the standard approach for most elective operations. The numerous advantages of laparoscopy such as early recovery, lower postoperative pain, reduced surgical trauma and blood loss, lower complication rate and mortality, and better cosmetic effect have made it the method of choice in most centers [14-19]. Initially it was used only for cases expected to be easy and hassle-free, mainly idiopathic thrombocytopenic purpura (ITP) and hemolytic anemias with nonenlarged spleens [20, 21]. Later, growing experience allowed for safe use of this method even in difficult cases including massive splenomegaly [22-25]. Laparoscopic splenectomy may also be safely performed in patients at high risk of complications related to clotting disorders including end-stage thrombocytopenia [26, 27].

After more than a quarter of a century it is believed that the technique of LS is more or less standardized [28-30]. However, most reports do not concentrate on differences in the surgical technique, which in our opinion are crucial. There are publications that focus mostly on surgical access to the peritoneal cavity rather than the technique of dissection of the splenic hilum and control of the vascular pedicle of the spleen [9, 10, 31, 32]. In the technique referred to as "vessels first" the entire splenic hilum including branches of all vessels, perivascular fat and lymphatic tissue was dissected away in one block from the pancreatic tail and removed together with the spleen. The main benefit of this approach was cost-effectiveness as it did not require the use of a vascular stapler - very popular in those times, but expensive. Even though economic issues are not analyzed in this paper, we believe that the "vessels first" technique was much less expensive and this aspect was most important for us in those times. We could document its feasibility and safety [11, 12]. With growing experience we found that it is related to relatively high incidence of various local complications including abscesses and fluid collections in the splenic bed, pancreatitis and pancreatic fistulas. We found evidence supporting this observation in the present study. The rate of those complications was almost twice as high in this group. This could be the result of dissection very close to the pancreatic parenchyma, which may cause direct injury, burns and ischemia of the pancreatic tail, leading to the abovementioned complications. Introduction of new generations of energy devices that allow for safe closure of relatively large vessels without clips resulted in a change in the operative approach. The dissection plane could be transferred from the pancreatic parenchyma to the splenic parenchyma. This allowed for protection of the pancreatic tail and resulted in a decrease in the risk of its injury. The reduction of local complications was documented in our study. There are more benefits of this technique. It is less time-consuming and is associated with lower blood loss and a lower conversion rate. The technique itself has some limitations. The caliber of vessels safely closed by energy devices is in the range 5-7 mm [33-35]. Usually in cases of non-enlarged spleens this is enough. However, sometimes, even in those cases, the diameter of branches in the splenic hilum, close to the splenic parenchyma, may be larger. There are two possible approaches to this situation. If those large-caliber vessels can be identified in the splenic hilum they can be individually clipped before transection. However, this technique may be difficult and time-consuming when numerous dilated branches are found, and this makes the procedure rather troublesome. We use a different method more frequently in cases when we expect to find larger vessels. In those patients the "vessels first" approach is still the primary technique, as it requires identification and isolation of only two vessels: the main trunks of the splenic artery and vein. Nowadays the "vessels first" technique is used mostly for difficult cases of large spleens or portal 
hypertension, which can explain, at least partially, the higher conversion rate in this group.

Our study has certain limitations typical for a single-center retrospective analysis. There is a potential bias regarding the use of postoperative drainage. At the beginning we routinely introduced at least one drain after each splenectomy. Later we stopped this practice, limiting the use of drains to complicated cases, for example involving injuries of the pancreatic tail [36]. The drains are known to be directly related to the occurrence of surgical site infections, and the difference in the rate of those complication is one of the most important results of the current study. Unfortunately, there is a lack of reliable data concerning recent use of drains, and we could not include this parameter in our analysis. Another limitation is the fact that in this analysis we did not include potential postoperative complications that might have occurred later than 30 days after discharge. This could certainly influence the overall complication rate.

\section{Conclusions}

Postoperative outcome after LS is related to the technique of dissection and control of the splenic vascular pedicle. The "vessels first" technique is associated with longer operative time, higher blood loss and increased risk of conversion. The approach referred to as "hilar transection" is associated with lower incidence of local complications related most likely to accidental injury of the pancreatic tail. All those data favor the latter method, although in the case of a large caliber of splenic vessels the "vessels first" approach remains the technique of choice.

\section{Conflict of interest}

The authors declare no conflict of interest.

\section{References}

1. Dionigi R, Boni L, Rausei S, Rovera F, Dionigi G. History of splenectomy. Int I Surg 2013; 11 (Suppl 1): S42-3.

2. Carroll BJ, Phillips EH, Semel CJ, et al. Laparoscopic splenectomy. Surg Endosc 1992; 6: 183-5.

3. Delaitre B, Maignien B. Laparoscopic splenectomy: technical aspects. Surg Endosc 1992; 6: 305-8.

4. Delaitre B, Maignien B. Splenectomy by the laparoscopic approach. Report of a case. Presse Med 1991; 20: 2263.

5. Gutierrez G, Reines HD, Wulf-Gutierrez ME. Clinical review: hemorrhagic shock. Crit Care 2004; 8: 373-81.
6. Kathariya R, Devanoorkar A, Jain H. Intra-operative hemorrhage: a review of literature. Med Diagnostic Methods 2013; 2: $1-5$.

7. Expert team. Polish Guidelines for the Treatment with Blood, Its Components and with Blood Products in Medical Entities. WEMA Wydawnictwo-Poligrafia, Warsaw 2014.

8. Clavien PA, Barkun J, de Oliveira ML, et al. The Clavien-Dindo classification of surgical complications. Ann Surg 2009; 250: 187-96.

9. Budzyński A, Matłok M, Pędziwiatr M, et al. SILS (single incision laparoscopic surgery) - new surgical approach to peritoneal cavity. Adv Med Sci 2011; 56: 18-24.

10. Pędziwiatr M, Matłok M, Major P, et al. Laparoscopic surgery of the spleen through single umbilical incision. Videosurgery Miniinv 2013; 8: 8-12.

11. Budzyński A, Bobrzyński A, Krzywoń J, et al. Technika "vessel first" w technicznie trudnej splenektomii laparoskopowej. Pol J Surg 2002; 74: 789-96.

12. Budzynski A, Bobrzynski A, Krzywon J. Laparoscopic surgery of the spleen. Przegl Lek 2001; 58: 158-61.

13. Motheral B, Brooks J, Clark MA, et al. A checklist for retrospective database studies - report of the ISPOR task force on retrospective databases. Value Heal 2003; 6: 90-7.

14. Habermalz B, Sauerland S, Decker G, et al. Laparoscopic splenectomy: the clinical practice guidelines of the European Association for Endoscopic Surgery (EAES). Surg Endosc 2008; 22: 821-48.

15. Corcione F, Pirozzi F, Aragiusto G, et al. Laparoscopic splenectomy: experience of a single center in a series of 300 cases. Surg Endosc Other Interv Tech 2012; 26: 2870-6.

16. Rosen M, Brody F, Walsh RM, et al. Outcome of laparoscopic splenectomy based on hematologic indication. Surg Endosc Other Interv Tech 2002; 16: 272-9.

17. Bai YN, Jiang H, Prasoon P. A meta-analysis of perioperative outcomes of laparoscopic splenectomy for hematological disorders. World J Surg 2012; 36: 2349-58.

18. Moris D, Dimitriou N, Griniatsos J. Laparoscopic splenectomy for benign hematological disorders in adults: a systematic review. In Vivo 2017; 31: 291-302.

19. Chen J, Ma R, Yang SZ, et al. Perioperative outcomes of laparoscopic versus open splenectomy for nontraumatic diseases: a meta-analysis. Chin Med J (Engl) 2014; 127: 2504-10.

20. Radkowiak D, Zychowicz A, Lasek A, et al. 20 years' experience with laparoscopic splenectomy. Single center outcomes of a cohort study of 500 cases. Int J Surg 2018; 52: 285-92.

21. Zheng D, Huang CS, Huang SB, Zheng CX. Laparoscopic splenectomy for primary immune thrombocytopenia: current status and challenges. World J Gastrointest Endosc 2016; 8: 610-5.

22. Al-Mulhim AS. Laparoscopic splenectomy for massive splenomegaly in benign hematological diseases. Surg Endosc Other Interv Tech 2012; 26: 3186-9.

23. Koshenkov VP, Németh ZH, Carter MS. Laparoscopic splenectomy: outcome and efficacy for massive and supramassive spleens. Am J Surg 2012; 203: 517-22.

24. Heniford BT, Park A, Walsh RM, et al. Laparoscopic splenectomy in patients with normal-sized spleens versus splenomegaly: does size matter? Am Surg 2001; 67: 854-7. 
25. Somasundaram SK, Massey L, Gooch D, et al. Laparoscopic splenectomy is emerging "gold standard" treatment even for massive spleens. Ann R Coll Surg Engl 2015; 97: 345-8.

26. Chen X, Peng B, Cai Y, et al. Laparoscopic splenectomy for patients with immune thrombocytopenia and very low platelet count: is platelet transfusion necessary? J Surg Res 2011; 170: e225-32.

27. Wu Z, Zhou J, Li J, et al. The feasibility of laparoscopic splenectomy for ITP patients without preoperative platelet transfusion. Hepatogastroenterology 2012; 59: 81-5.

28. Feldman LS. Laparoscopic splenectomy: standardized approach. World J Surg 2011; 35: 1487-95.

29. Fisichella PM, Wong YM, Pappas SG, Abood GJ. Laparoscopic splenectomy: perioperative management, surgical technique, and results. J Gastrointest Surg 2014; 18: 404-10.

30. Deeb AP, Kim MJ, Fleming FJ, et al. The impact of operative approach in elective splenectomy: a multivariate analysis of outcomes from the NSQIP database. Surg Laparosc Endosc Percutan Tech 2012; 22: 415-9.

31. Qian D, He Z, Hua J, et al. Hand-assisted versus conventional laparoscopic splenectomy: a systematic review and meta-analysis. ANZ J Surg 2014; 84: 915-20.

32. Park A, Targarona EM, Trías M. Laparoscopic surgery of the spleen: state of the art. Langenbeck's Arch Surg 2001; 386: 230-9.

33. Zhan XL, Ji Y, Wang YD. Laparoscopic splenectomy for hypersplenism secondary to liver cirrhosis and portal hypertension. World J Gastroenterol 2014; 20: 5794-800.

34. Entezari K, Hoffmann P, Goris M, et al. A review of currently available vessel sealing systems. Miniim Invasive Ther Allied Technol 2007; 16: 52-7.

35. Smith R, Pasic R. The role of vessel sealing technologies in laparoscopic surgery. Surg Technol Int 2008; 17: 208-12.

36. Major P, Matłok M, Pędziwiatr M, Budzyński A. Do we really need routine drainage after laparoscopic adrenalectomy and splenectomy? Videosurgery Miniinv 2012; 7: 33-9.

Received: 16.12.2017, accepted: 20.04.2018. 